\title{
Phase I/II trial of immunogenicity of a human papillomavirus (HPV) type 16 E7 protein-based vaccine in women with oncogenic HPV-positive cervical intraepithelial neoplasia
}

\author{
Sophie Hallez ${ }^{1}$, Philippe Simon ${ }^{2}$, Frédéric Maudoux ${ }^{1}$, Jean Doyen ${ }^{4}$, Jean-Christophe Noël ${ }^{3}$, Aude Beliard ${ }^{4}$, \\ Xavier Capelle ${ }^{4}$, Frédéric Buxant ${ }^{2}$, Isabelle Fayt ${ }^{3}$, Anne-Cécile Lagrost ${ }^{5}$, Pascale Hubert ${ }^{5}$, Colette Gerday ${ }^{4}$, \\ Arsène Burny ${ }^{1}$, Jacques Boniver ${ }^{5}$, Jean-Michel Foidart ${ }^{4}$, Philippe Delvenne ${ }^{5}$, Nathalie Jacobs ${ }^{5}$ \\ ${ }^{l}$ Chimie Biologique, Institut de Biologie et de Médecine Moléculaires, Université Libre de Bruxelles, 12 rue des Professeurs Jeener et \\ Brachet, 6041 Gosselies, Belgium \\ ${ }^{2}$ Department of Obstetrics and Gynaecology, Hôpital Erasme, 1070 Brussels, Belgium \\ ${ }^{3}$ Department of Clinical Pathology, Hôpital Erasme, 1070 Brussels, Belgium \\ ${ }^{4}$ Department of Gynecology, University of Liège, 4000 Liège, Belgium \\ ${ }^{5}$ Department of Pathology, CRCE, University of Liège, CHU Sart-Tilman, 4000 Liège, Belgium
}

\begin{abstract}
Purpose: Infection with oncogenic human papillomavirus (HPV) and HPV-16 in particular is a leading cause of anogenital neoplasia. High-grade intraepithelial lesions require treatment because of their potential to progress to invasive cancer. Numerous preclinical studies have demonstrated the therapeutic potential of E7-directed vaccination strategies in mice tumour models. In the present study, we tested the immunogenicity of a fusion protein (PD-E7) comprising a mutated HPV-16 E7 linked to the first 108 amino acids of Haemophilus influenzae protein D, formulated in the GlaxoSmithKline Biologicals adjuvant AS02B, in patients bearing oncogenic HPVpositive cervical intraepithelial neoplasia (CIN). Methods: Seven patients, five with a CIN3 and two with a CIN1, received three intramuscular injections of adjuvanted PD-E7 at 2-week intervals. Three additional CIN1 patients received a placebo. CIN3 patients underwent conization 8 weeks postvaccination. Cytokine flow cytometry and ELISA were used to monitor antigen-specific cellular and antibody responses from blood taken before and after vaccine or placebo injection. Results: Some patients had preexisting systemic IFN- $\gamma$ CD4 ${ }^{+}(1 / 10)$ and $\mathrm{CD}^{+}(5 / 10)$ responses to PD-E7. Vaccination, not placebo injection, elicited systemic specific immune responses in the majority of the patients. Five vaccinated patients $(71 \%)$ showed significantly increased IFN- $\gamma$ $\mathrm{CD}^{+}$cell responses upon PD-E7 stimulation. Two responding patients generated long-term T-cell immunity toward the vaccine antigen and E7 as well as a weak $H$. influenzae protein D (PD)-directed CD4 ${ }^{+}$response. All the vaccinated patients, but not the placebo, made significant E7- and PD-specific IgG. Conclusions: The encouraging results obtained from this study performed on a limited number of subjects justify further analysis of the efficacy of the PD-E7/AS02B vaccine in CIN patients.
\end{abstract}

Keywords: CD4 ; CD8 ; human papillomavirus ; IFN- $\gamma$; immunotherapy

\section{Introduction}

Persisting infection with oncogenic human papillomavirus (HPV) is a significant risk factor for the development of anogenital intraepithelial lesions that may progress to cancer [12]. DNA from these high-risk HPVs is detected in more than $99 \%$ of cervical cancers, $50 \%$ of anal, penile, vulvar and vaginal cancers, but also in more than $20 \%$ of oral, laryngeal and nasal cancers [38]. Although infection, even with high-risk HPV and low-grade cervical intraepithelial neoplasia (CIN1), are frequently cleared spontaneously [25], women who harbour oncogenic HPV are more likely to develop high-grade lesions (CIN2/3) than women who do not [18]. Currently, high-grade lesions (CIN2/3) detected by screening are treated because it is impossible to predict which CIN will progress to invasive tumours. However, conventional ablative physical or chemical therapeutic approaches are not optimal as they might lead both to recurrence and adverse events [26, 29, 31].

An HPV-directed vaccine capable of eradicating infected cells and protecting against new infections would represent a great medical benefit for patients. Much research is presently focused on setting up such vaccines and HPV-16-directed vaccine in particular because this viral type is the most frequently encountered HPV in CIN lesions and cancer $[8,21]$. The main targets of immunotherapeutic strategies are the E6 and E7 viral oncoproteins, as they are expressed at all stages of the virus life cycle and particularly in cancer cells [24, 28]. These proteins have been reported to contain both MHC class I- and П-restricted epitopes recognized by human and mouse T cells $[16,35]$. Numerous preclinical studies have demonstrated the ability of HPV-16 E7-based vaccinations to generate protective as well as therapeutic antitumour immunity, at least in some mice tumour models $[4,14,21,22]$. 
These promising results have justified the evaluation of the safety and immunogenicity of some HPV-16/18 E6/E7-directed vaccines in patients bearing either anogenital cancer or high-grade intraepithelial lesions: recombinant vaccinia viruses, peptides or proteins mixed or not with adjuvant, dendritic cells pulsed with tumour lysate and plasmidic DNA encapsulated in microparticles [5, 8, 10, 17, 19, 27, 32, 34, 36]. The clinical efficacy of these treatments remains to be demonstrated.

In the present multicentre study, we investigated the immunogenicity of a HPV-16 E7 fusion protein (PD-E7) formulated in an adjuvant system containing MPL, QS-21 and oil-in-water emulsion (GSK AS02B) in patients with oncogenic HPV-positive CIN. Preclinical studies performed in C57BL6 mice have shown that this antigenic formulation induces regression of preestablished $\mathrm{TC} 1$ and $\mathrm{C} 3$ tumours [9]. The cellular immune response to vaccination was monitored from PBMCs briefly stimulated in vitro with antigenic proteins, using cytokine flow cytometry (CFC). Our data show that vaccination with PD-E7/GSKAS02B induces both cellular and humoral immune responses, characterized by a PD-E7-specific production of IFN- $\gamma$ from $\mathrm{CD}^{+} \mathrm{T}$ cells and low titres of E7- and PD-specific IgG.

\section{Materials and methods}

\section{Subjects}

CIN1 and CIN3 patients were recruited from different centres (University Hospital of Liege and Erasme Hospital, respectively). The eligibility criteria for CIN1 patients were the persistence of a low-grade squamous intraepithelial lesion as diagnosed by cytological examination and biopsy-proven CIN1 for a minimum of 3 months with detection of oncogenic HPV (detected by Hybrid Capture II System, Digene, Gaithersburg, MD, USA). The eligibility criteria for CIN3 patients have been previously described [33]. Briefly, they had highgrade squamous intraepithelial lesion as diagnosed by single-layer cytology and biopsy-proven CIN3. Colposcopy demonstrated exocervical lesions with less than 3-mm involvement of the endocervical canal. For CIN3 lesions, the PCR products obtained following DNA amplification with MY09/ MY11 primers were typed HPV-16 by the DEIA method [3, 6, 30]. A total of eleven patients, ages 20-51, were enrolled after providing signed informed consent. One patient was withdrawn before the end of the study [33].

\section{Vaccination protocol}

Patients were injected intramuscularly in the buttock at 0, 2 and 4 weeks with $200 \mu \mathrm{g}$ of an HPV-16 E7-derived fusion protein (PD-E7, C24G/E26Q mutated E7 protein fused at its amino-terminal end to the first 108 amino acids of Haemophilus influenzae protein D and tagged at its carboxy-terminal end with six histidines) formulated with $500 \mu \mathrm{l}$ of the GlaxoSmithKline (GSK) Adjuvant System AS02B (100- $\mu$ g MPL, 100- $\mu$ g QS-21 and 250- $\mu$ l oil-in-water emulsion) [9]. Controls were injected with $500 \mu \mathrm{l}$ of a $\mathrm{NaCl} 0.9 \%$ solution (placebo). The adjuvant known to induce local adverse reactions was not used as placebo because of ethical concerns. The vaccination protocol was single blind. The study vaccine has been kindly provided by GSK Biologicals, Belgium. Patients were followed up at the hospital $2 \mathrm{~h}$ after each vaccination for observation.

\section{Specimen collection}

Calparinated blood $(25 \mathrm{ml})$ was obtained at each vaccination/placebo injection date, 4 weeks after the last injection (conization date for CIN3 patients) and at the end of the study (between weeks 35 and 60). An additional blood sample was obtained 2 years post-vaccination for two CIN3 patients.

\section{Clinical follow-up}

Patients were clinically monitored at weeks $0,2,4,8 \pm 1,20 \pm 1,32 \pm 3$ and $44 \pm 6$. Briefly, disease status was monitored at each visit using colposcopy, cervical cytology and detection of cervical HPV DNA. The safety of the treatment was assessed by recording vital signs, local and systemic symptoms, serious adverse events as well as haematological and biochemistry parameters. The protocol was approved by the ethics committee of each study centre.

\section{Cytokine production}

Cell preparation and antigenic stimulation

PBMCs were separated from $25 \mathrm{ml}$ of fresh calparinated blood diluted with one volume of Hank's solution $\mathrm{pH}$ 7.4, using a Ficoll-Hypaque density gradient. Autologous plasma, removed from the top of the gradient, was stored at $-70^{\circ} \mathrm{C}$ for serology. Fresh PBMCs, $2 \times 10^{6} / \mathrm{ml}$ in X-Vivo 20 medium (BioWhittaker) supplemented with $20 \mathrm{U} / \mathrm{ml} \mathrm{IL-2} \mathrm{in} \mathrm{14-ml} \mathrm{round-bottom} \mathrm{polypropylene} \mathrm{tubes,} \mathrm{were} \mathrm{cultured} \mathrm{overnight} \mathrm{at} 37^{\circ} \mathrm{C}$ with or without equimolar amount of activators: $5 \mu \mathrm{g} / \mathrm{ml} \mathrm{PD-E7,} 3 \mu \mathrm{g} / \mathrm{ml} \mathrm{His}_{6}$-E7 [11], $7.5 \mu \mathrm{g} / \mathrm{ml}$ full-length recombinant $H$. influenzae protein D (PD, GSK Biologicals, Belgium), $0.4 \mu \mathrm{g} / \mathrm{ml}$ PHA (Innogenetics). Brefeldin A (10 $\mu \mathrm{g} / \mathrm{ml}$, Sigma) was added during the last $3 \mathrm{~h}$ of culture. In the blocking experiment, $10 \mu \mathrm{g} / \mathrm{ml}$ of dialyzed W6/32 monoclonal antibody (DAKO) was added $30 \mathrm{~min}$ before the antigen. 


\section{Cytokine flow cytometry (CFC) assay}

For each culture condition, two to three separate staining experiments were performed $\left(1.5 \times 10^{6}\right.$ cells $\left./ \mathrm{staining}\right)$. Cells, concentrated in $100 \mu \mathrm{l}$ of the culture medium, were stained for cell surface molecules at $4^{\circ} \mathrm{C}$ during 20 min with: (i) anti-CD4-PE $(5 \mu \mathrm{l})$ and anti-CD8-PerCP (10 $\mu \mathrm{l})$, (ii) anti-CD3-PE (5 $\mu \mathrm{l})$ and anti-CD8-PerCP (10 $\mu \mathrm{l})$, (iii) anti-CD3-PerCP $(10 \mu \mathrm{l})$, anti-CD16-PE $(5 \mu \mathrm{l})$ and anti-CD56-PE (5 $\mu \mathrm{l})$ (Becton Dickinson). After washing with PBS, cells were fixed for $20 \mathrm{~min}$ at $20^{\circ} \mathrm{C}$ with $70 \mu 1$ of solution A (kit FIX and PERM, An der Grub). After an additional washing with PBS, they were simultaneously permeabilized with $70 \mu 1$ of solution B (kit FIX and PERM) and stained with $7 \mu \mathrm{l}$ of anti-IFN- $\gamma$-FITC (Becton Dickinson) for 20 min at $20^{\circ} \mathrm{C}$. After a final wash, cells were resuspended in $400 \mu \mathrm{l}$ of $1 \%$ paraformaldehyde in PBS and acquisition was performed within $24 \mathrm{~h}$ on 250,000 events per tube with a flow cytometer. Analysis was performed using Cell-Quest on an $\mathrm{SSC} / \mathrm{FSC}$ gate on viable lymphocytes. According to the fluorescence markers, the following regions were defined using dot plots and analysed for cytokine producing cells: (1) $\mathrm{CD}^{+} \mathrm{CD}^{-}$and (2) $\mathrm{CD} 4^{-} \mathrm{CD} 8^{+}$(staining i), (3) $\mathrm{CD}^{+} \mathrm{CD}^{+}$(staining ii) and (4) $\mathrm{CD}^{-} \mathrm{CD} 16 / \mathrm{CD}^{-} 6^{+}$(staining iii). Results were expressed as the percentage of cytokine-positive cells in the defined region. Where indicated, background (no activator) was subtracted. A PBMC sample was considered to respond to an antigen when the percentage of T cells producing IFN- $\gamma$ after stimulation with that antigen was $>0.1$ and $\geq$ fivefold its background value.

\section{ELISA}

Overnight supernatants from PBMC cultures, supplemented with $0.5 \%$ BSA and stored at $-70^{\circ} \mathrm{C}$, were analysed for IFN- $\gamma$ content in a specific capture ELISA according to the manufacturer's instructions (R\&D Systems).

\section{Serology}

HPV-16 E7- and H. influenzae protein D-specific antibodies were measured from the patient's plasma using ELISA. Microtiter Maxisorp Nunc immunoplates were coated with $\mathrm{His}_{6}$-E7 $(5 \mu \mathrm{g} / \mathrm{ml})$ or PD $(2.5 \mu \mathrm{g} / \mathrm{ml})$ proteins in 0.1-M carbonate buffer $\mathrm{pH} 9.6$, overnight at $4^{\circ} \mathrm{C}$. Wells were blocked with $\mathrm{PBS} 3 \% \mathrm{BSA}$ for $2 \mathrm{~h}$ at $20^{\circ} \mathrm{C}$. Test plasma were serially diluted in PBS $1 \%$ BSA $0.1 \%$ Tween 20 and added to the plate wells in duplicate. After 2-h incubation at $37^{\circ} \mathrm{C}$, Ag-specific antibodies were detected by incubating the plates for $2 \mathrm{~h}$ at $37^{\circ} \mathrm{C}$ with sheep antibodies directed against human IgGs, linked to horseradish peroxidase (Amersham) $(1: 2,000$ in PBS 1\% BSA $0.1 \%$ Tween 20). After a last wash, plates were developed with OPD at $20^{\circ} \mathrm{C}$, stopped with $2-\mathrm{N}$ $\mathrm{H}_{2} \mathrm{SO}_{4}$ and absorbance read at $490 \mathrm{~nm}$. Specific IgG titres were recorded as the reciprocal of plasma dilution at an absorbance of 0.6 .

\section{Statistical analysis of the data}

Where indicated, statistical analyses were performed using either paired Wilcoxon signed rank tests or Student's paired $t$-tests.

\section{Results}

Ten patients, with CIN1 or CIN3 being typed either HPV-16 or positive for oncogenic HPV, have completed the study protocol (Table 1). Seven of those patients received three intramuscular injections of PD-E7 fusion protein mixed to the GSK adjuvant AS02B at 2-week intervals and three were injected with the placebo (Table 1). CIN3 patients underwent conization 4 weeks after the last vaccination and CIN1 patients were followed up at close intervals, except for two women with persistent cytological atypia who were treated either by laser or by conization 6 months after vaccination. The vaccine was well tolerated by all the patients with no serious adverse events either reported or detected ([33] and data not shown).

Table 1 Clinical characteristics of the study patients

\begin{tabular}{llll}
\hline Patient number & Age at enrolment & Lesion & HPV type \\
\hline V1 $^{\text {a }}$ & 20 & CIN3 & 16 \\
V2 & 42 & CIN3 & 16 \\
V4 & 40 & CIN3 & 16 \\
V5 & 37 & CIN3 & 16 \\
V6 & 29 & CIN3 & 16 \\
V7 & 27 & CIN1 & 16 \\
V8 & 28 & CIN1 & Oncogenic \\
P1 & 35 & CIN1 & 16 \\
P2 & 24 & CIN1 & Oncogenic \\
P3 & 29 & CIN1 & Oncogenic \\
\hline
\end{tabular}

\footnotetext{
${ }^{a} \mathrm{~V}$ patients received the $\mathrm{PD}-\mathrm{E} 7 / \mathrm{GSK}$ AS02B vaccine

${ }^{\mathrm{b}}$ Oncogenic HPV types (HPV-16, 18, 31, 33, 35, 39, 45, 51, 52, 56, 58, 59, 69) detected by Hybrid Capture II Assay (Digene)

${ }^{c} \mathrm{P}$ patients received the placebo
} 


\section{Systemic cellular immune responses to vaccination}

For vaccinated (V1-V8) as well as for placebo-injected (P1-P3) patients, the intracellular IFN- $\gamma$ production in response to PD-E7 stimulation was analysed at weeks 0 (pretreatment), 2 (post first injection), 4 (post second injection), 8 (post third injection) and between weeks 35 and 60, except for V2 and V4. In the absence of antigen stimulation, very low percentages of cytokine-producing $\mathrm{CD}^{+}(0.029 \pm 0.034)$ and $\mathrm{CD} 8^{+}(0.033 \pm 0.029)$ cells were enumerated (data not shown). As depicted in Fig. 1, a preexisting CD8 ${ }^{+}$response to PD-E7 was detected in five $(50 \%)$ patients $(\mathrm{V} 2, \mathrm{~V} 5-6, \mathrm{~V} 8, \mathrm{P} 3)$, with only one also showing a CD4 ${ }^{+}$response (V6). Vaccination increased the frequency of $\mathrm{CD} 8^{+}$cells producing IFN- $\gamma$ in response to the vaccine antigen in five out of seven patients (V1-2, V4-5, V7; $P<0.05)$. A single vaccine injection increased the PD-E7-directed IFN- $\gamma$ T-cell responses in V2 and V4. In contrast, V1, V5 and V7 generated a detectable response to vaccination only after three injections. Four weeks after the third vaccine injection, the PD-E7-specific CD $8^{+}$IFN- $\gamma$ response was the highest for V1 and V5, and 2.5 to 2.7 times lower for V2, V4 and V7. Lower and more variable levels of CD4 cells responses were detected, with the highest in V5. IFN- $\gamma$ response to vaccination appeared transient, as shown by an undetectable (V1) or low (V5, V7) reactivity to PD-E7 at weeks 56, 46 and 35 postvaccination, respectively. The kinetics of PD-E7-specific T-cell responses were similar for nonresponding vaccinated patients compared with placebo-injected ones.

Fig. 1A, B Kinetics of intracellular IFN- $\gamma$ production following injection with PD-E7/GSK AS02B or placebo. For all patients, PBMCs prepared at each time point were incubated overnight in vitro with or without PD-E7. Cells were subsequently stained with antibodies to CD4, CD8 and IFN- $\gamma$ (CFC assay). From 250,000 events gated on viable lymphocytes, CD4 ${ }^{-} \mathrm{CD} 8^{+}$and $\mathrm{CD}^{-} 4^{+} \mathrm{CD} 8$ cells were analysed for IFN- $\gamma$ production. Results are expressed as the percentage of IFN- $\gamma$-positive $\mathrm{CD}^{+}$and $\mathrm{CD} 4^{+}$cells from PD-E7stimulated PBMCs, with the basal percentage in the absence of antigen subtracted, relative to time postvaccination. For CIN3 patients, background values were $0.014 \pm 0.008 \%$ for $\mathrm{CD}^{+}$cells and $0.018 \pm 0.013 \%$ for $\mathrm{CD} 8^{+}$cells, whereas for $\mathrm{CIN} 1$ patients, values were $0.040 \pm$ $0.030 \%$ and $0.049 \pm 0.034 \%$, respectively. A V1-V6: CIN3, vaccinated; B V7-8: CIN1, vaccinated and P1-3: placebo-injected

A.

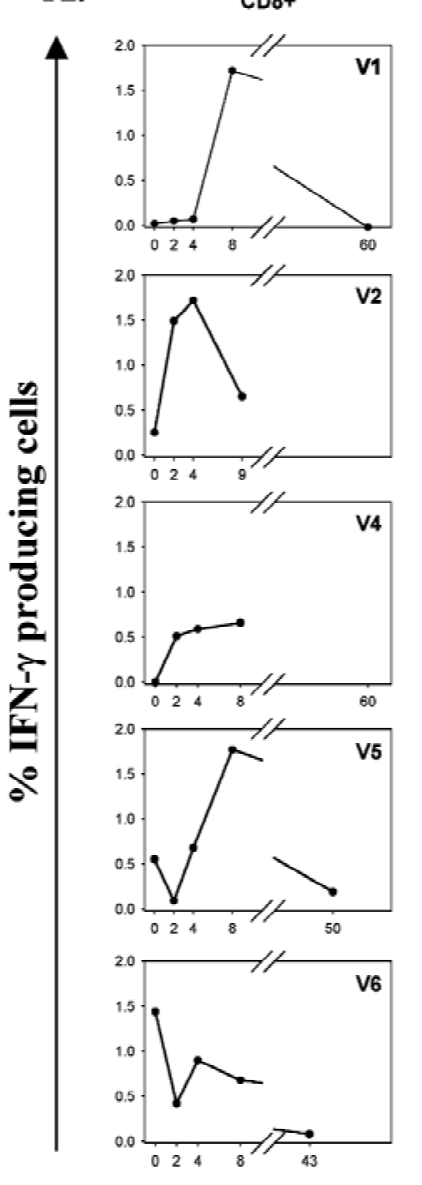

CD4+
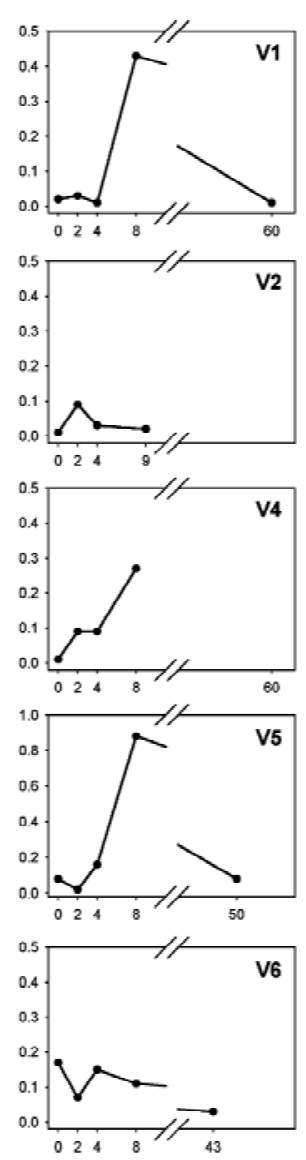

B.
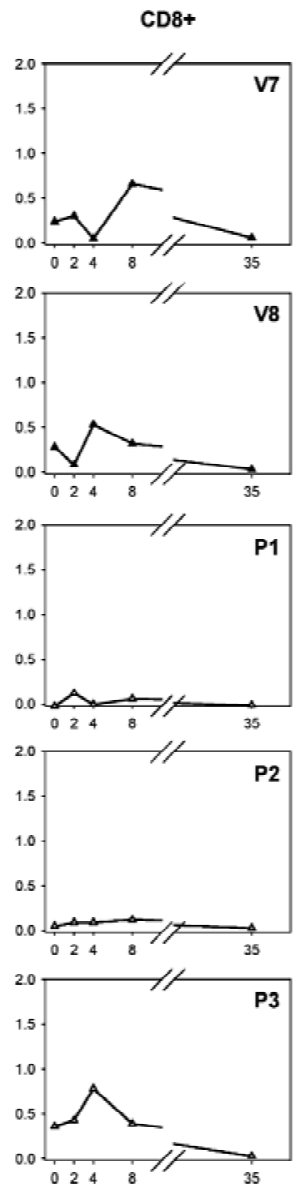

CD4+
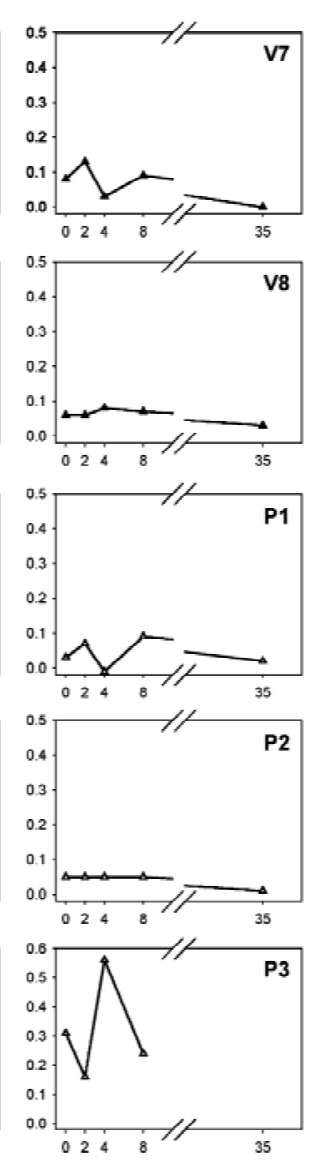

\section{Weeks post $1^{\text {st }}$ vaccination}

To assess the E7-specificity of the vaccine-induced responses, IFN- $\gamma$-producing cells were also counted after stimulation with the $\mathrm{His}_{6}$-E7 protein. From the five tested patients, only V1 and V5 developed a significant CD4 ${ }^{+}$ and $\mathrm{CD}^{+}$cell response to $\mathrm{His}_{6}$-E7 and with the same kinetics as those to PD-E7 (peak at week 8) (Fig. 2; 
$P<0.05)$. When tested 2 years postvaccination, $\mathrm{V} 1$ and $\mathrm{V} 5$ were revealed by $\mathrm{CFC}$ analysis to still generate strong IFN- $\gamma \mathrm{CD}^{+}$and $\mathrm{CD} 8^{+}$cell responses to both PD-E7 $(P<0.01)$ and $\mathrm{His}_{6}$-E7 $(P<0.01)$, and a weak CD4 ${ }^{+}$cell response to full length $\mathrm{PD}(P<0.05)$ (Fig. 3). These data suggest the establishment of a long-term IFN- $\gamma$ T-cell response to the vaccine antigen and most probably to E7 in at least $28 \%$ of the vaccinated patients.

Cytokine responses in prevaccine and postvaccine PBMCs were further confirmed by performing a specific ELISA on week 0 and week 8 PBMC supernatants. ELISA and CFC results were mostly concordant, with three among seven patients recorded as responding to vaccination with ELISA versus five with CFC. In agreement with our CFC data, the highest IFN- $\gamma$ levels were found in V1 and V5 PD-E7-stimulated postvaccine PBMC supernatants (Fig. 4A). The weak CFC responses of patients V2 (CIN3) and V7 (CIN1) were not detectable by ELISA. All the supernatants from the PD-E7-stimulated CIN1 PBMCs contain detectable levels of IFN- $\gamma$, whereas one placebo patient (P3) showed a higher amount of cytokine production in week 8 supernatant than in week 0 sample (Fig. 4).

Fig. 2 Kinetics of His ${ }_{6}$-E7-specific intracellular IFN- $\gamma$ production in vaccinated CIN3 patients. PBMCs prepared at each time point were stimulated overnight in vitro with no antigen or with $\mathrm{His}_{6}$-E7. Cells were subsequently stained with antibodies to CD4, $\mathrm{CD} 8$ and IFN- $\gamma$ (CFC assay). From 250,000 events gated on viable lymphocytes, IFN- $\gamma$-positive CD4 CD8 ${ }^{+}$and $\mathrm{CD} 4^{+} \mathrm{CD} 8{ }^{-}$cells were enumerated. Results are expressed as the percentage of IFN- $\gamma$-positive $\mathrm{CD} 8^{+}$and $\mathrm{CD}^{+}$cells from $\mathrm{His}_{6}$-E7-stimulated PBMCs, with the basal percentage in the absence of antigen subtracted relative to time postvaccination. The background values were $0.014 \pm 0.008 \%$ for $\mathrm{CD}^{+}$cells and $0.018 \pm 0.013 \%$ for $\mathrm{CD} 8^{+}$cells
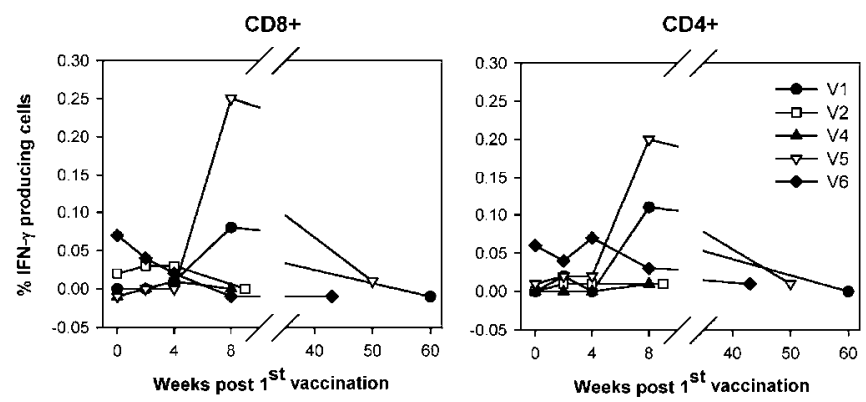

Fig. 3A, B Typical CFC analysis performed with PBMCs from patients V1 and V5, 2 years postvaccination, showing reactivity to $P D-E 7$ and His ${ }_{6}-E 7$, but not to $H$. influenzae protein D. PBMCs were stimulated overnight in vitro with no antigen or with PD-E7, $\mathrm{His}_{6}$-E7 or PD. Cells were subsequently stained with antibodies to CD4, CD8 and IFN- $\gamma$ and analysed by flow cytometry (CFC assay). For each stimulation condition, dot plots show the $\mathrm{CD} 8^{+} \mathrm{CD} 4{ }^{-}$and $\mathrm{CD} 8^{-} \mathrm{CD} 4^{+}$regions renamed $\mathrm{CD} 8^{+}$and $\mathrm{CD} 4$ cells, respectively (top graphs) and the percentage of IFN- $\gamma$-positive $\mathrm{CD}^{+}$cells (middle graphs) and $\mathrm{CD}^{+}$cells (bottom graphs). Results from V1 (A) and V5 (B) are presented

A.
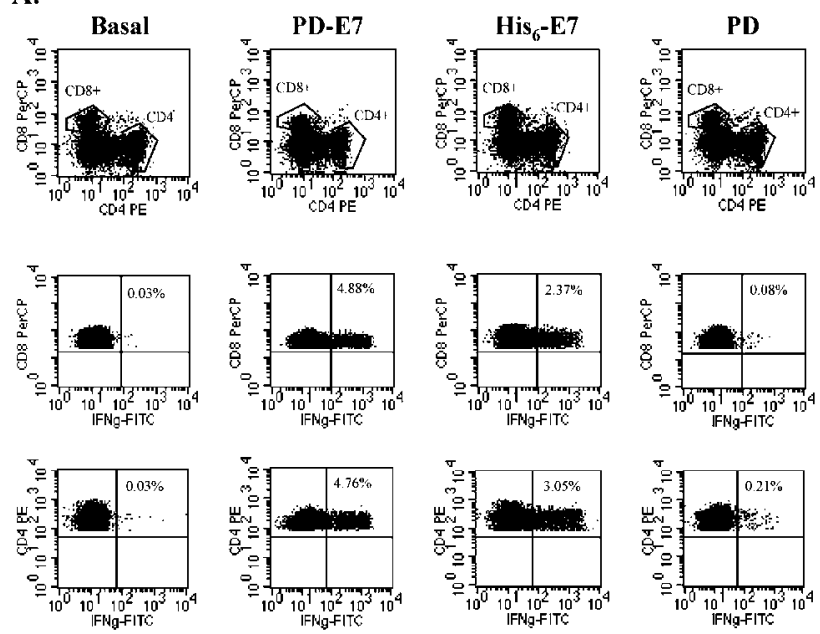

B.
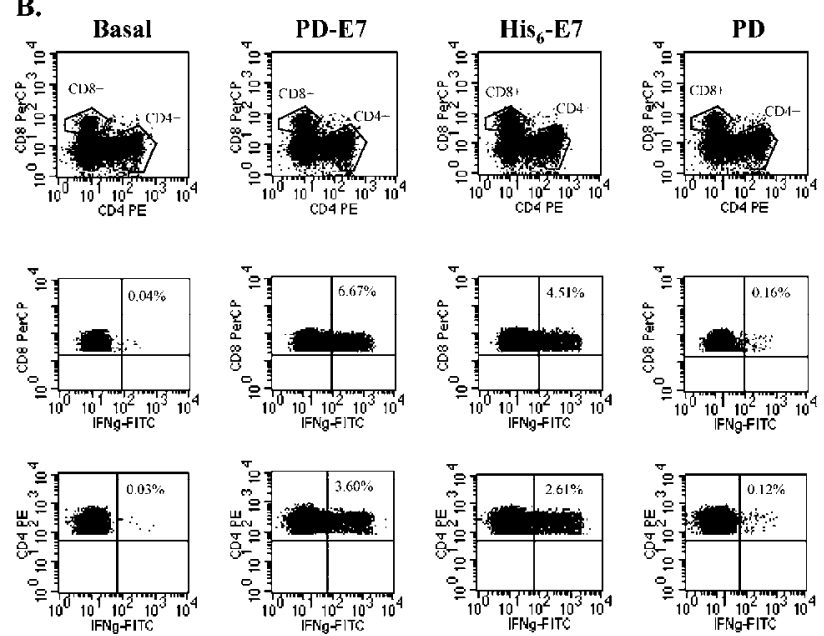
Fig. 4A, B Monitoring of IFN- $\gamma$ response to E7 proteins using ELISA. PBMCs prepared before and after vaccination/ placebo injection were stimulated overnight in vitro with no antigen or with PD-E7, and their supernatants were tested for IFN- $\gamma$ content using ELISA. Results from vaccinated (A) and placebo-injected (B) patients are presented

A.

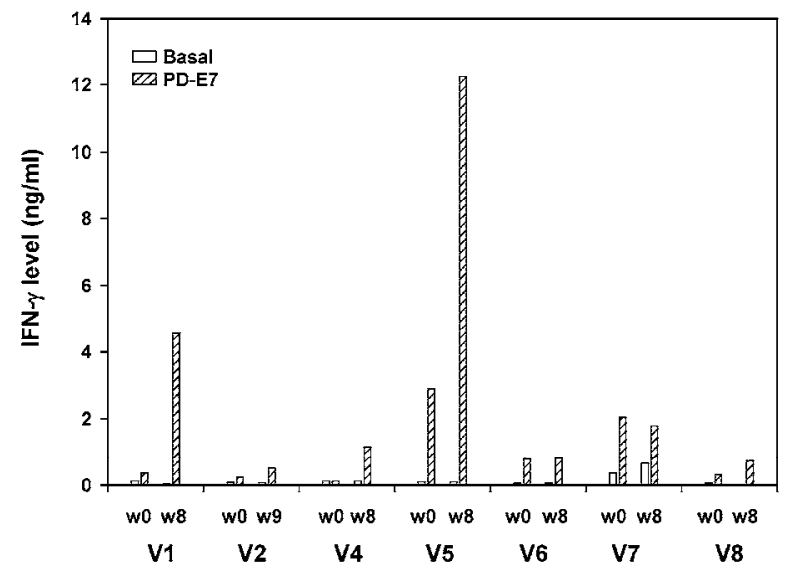

B.



Characterization of the CD8+ cells producing IFN- $\gamma$ in response to PD-E7 stimulation

We sought to further confirm that the IFN- $\gamma$ response to PD-E7, measured by CFC, was actually a T-cell response. Firstly, we compared the percentage of cytokine-producing cells within the $\mathrm{CD} 8^{+} \mathrm{CD} 4^{-}$and $\mathrm{CD} 8^{+} \mathrm{CD} 3^{+}$ PD-E7-stimulated populations that were of comparable size (data not shown). As shown in Fig. 5A, similar percentages of IFN- $\gamma$-producing cells were detected in both PBMC populations, at each time point and for all the tested patients. The good correlation between these two cells populations for IFN- $\gamma$ response $\left(r^{2}=0.85\right)$ further suggests their identity. Secondly, using a blocking antibody against HLA-A, HLA-B and HLA-C, we showed that the reactivity of $\mathrm{CD}^{+} \mathrm{CD} 4^{-}$cells to $\mathrm{PD}-\mathrm{E} 7$ was $\mathrm{MHC}$ class I-restricted (Fig. 5B), whereas that of $\mathrm{CD} 8^{-} \mathrm{CD} 4^{+}$ cells was not modified (Fig. 5C) and that of $\mathrm{CD}^{-} \mathrm{CD} 16 / 56^{+}$cells was slightly increased (Fig. 5D). The small percentages of $\mathrm{CD}^{+} \mathrm{CD}^{-}$(Fig. 5B) and $\mathrm{CD}^{-} \mathrm{CD} 4^{+}$(Fig. 5C) cells that spontaneously produced IFN- $\gamma$ were not affected by MHC class I blocking whereas that of CD3-CD16/56 cells was increased (Fig. 5D). These data suggest that IFN- $\gamma$-producing $\mathrm{CD}^{+} \mathrm{CD}^{-}$cells assessment reflects PD-E7-specific MHC class I-restricted T-cell responses. 
Fig. 5A-D CD8 ${ }^{+} C D 4^{-}$IFN- $\gamma$ response to PD-E7 as measured by CFC is a MHC class I-restricted T-cell response. A PBMCs prepared before and after vaccination were stimulated overnight in vitro with no antigen or with PD-E7 and subsequently stained with antibodies directed either to CD8, CD4 and IFN- $\gamma$, or CD8, CD3 and IFN- $\gamma$. The net PD-E7-specific response is expressed as the percentage of IFN- $\gamma$-producing $\mathrm{CD} 8^{+} \mathrm{CD} 4$ and $\mathrm{CD}^{+} \mathrm{CD}^{+}$cells (basal production was subtracted). B-D V6's PBMCs (week 43), preincubated or not with W6/32 monoclonal antibody, were stimulated overnight in vitro with no antigen or with PD-E7. Cells were then stained with antibodies directed either to CD4, CD8 and IFN- $\gamma$, or CD3, CD 16/56 and IFN- $\gamma$. For each stimulation condition the CD8 $8^{+} \mathrm{CD} 4$,

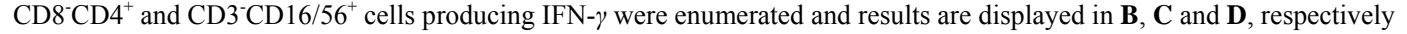
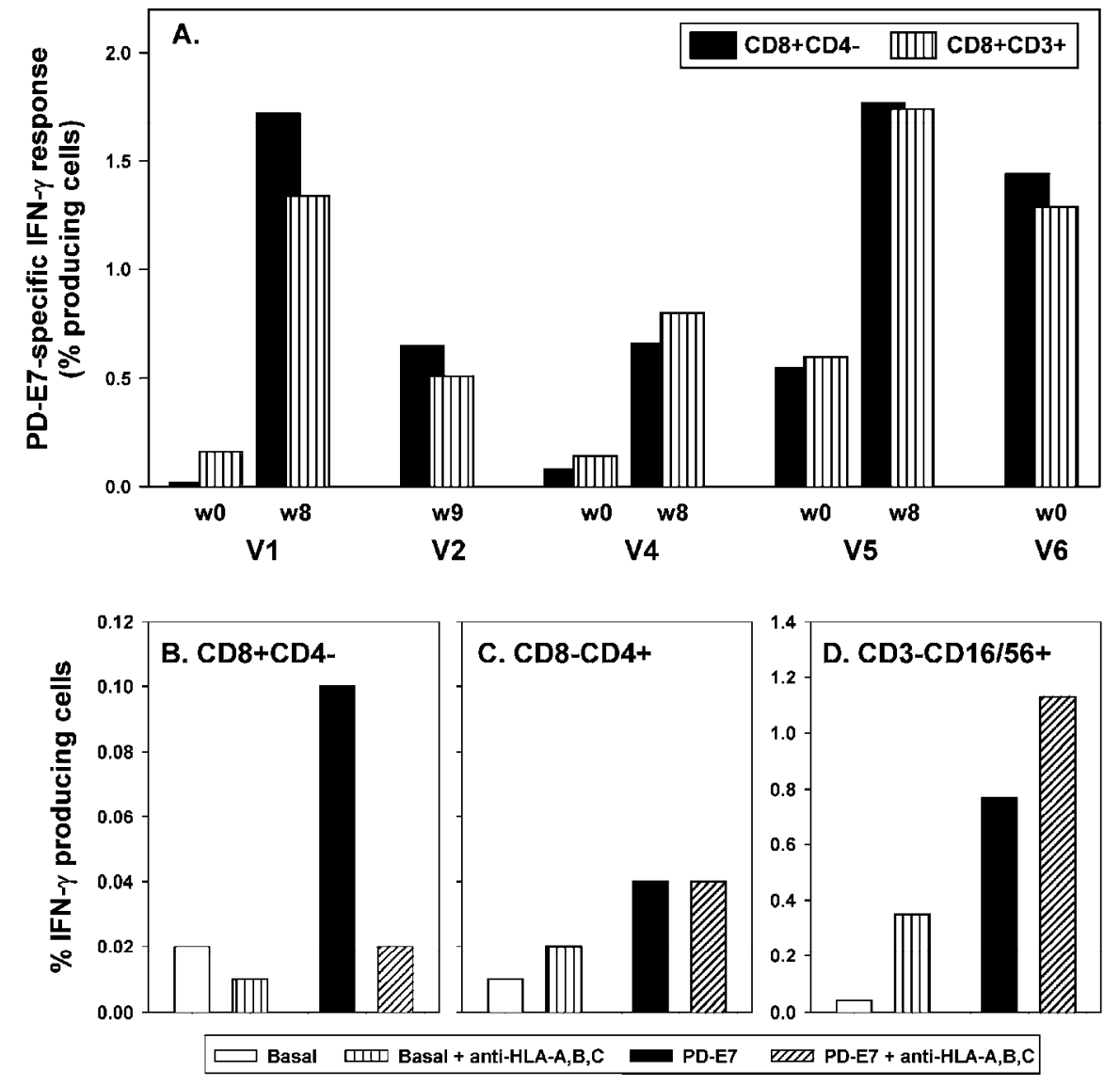

Humoral responses before and after vaccination

The titres of $\mathrm{His}_{6}$-E7- and PD-specific IgG in plasma are shown in Fig. 6. All the study patients had undetectable plasma IgG responses to either His $_{6}$-E7 or PD before treatment (Fig. 6; and data not shown). At 4 weeks after the final injection, all the vaccinated patients generated weak (V1-2, V4) or moderate (V5-8) anti-His 6 -E7 antibody responses $(P<0.05)$ whereas placebo-injected ones did not. Knowing that an IgG response is a surrogate marker for $\mathrm{CD}^{+} \mathrm{T}$-cell response, it is interesting to note that $\mathrm{V} 5$ is one out of the two patients who had a detectable $\mathrm{CD}^{+}{ }^{+} \mathrm{IFN}-\gamma$ response to $\mathrm{His}_{6}$-E7 at week 8 (Fig. 2). The reactivity of postvaccination plasma to $\mathrm{His}_{6}$-E7 was confirmed in a Western blot (data not shown). Six out of the seven vaccinated patients also developed a PDspecific IgG response $(P<0.05)$. The anti-PD IgG titres were low for V2 and V6 and moderate for V4-5, V7-8. The average anti-His 6 -E7 antibody titres postvaccination were 2.8-fold lower than their average anti-PD titres (341 vs 971). 
Fig. 6 Prevaccination and postvaccination humoral responses to E7 and H. influenzae protein D. For each of the vaccinated patients, antibodies to $\mathrm{His}_{6}-\mathrm{E} 7$ and PD were detected from plasma taken at weeks 0 (open symbol) and 8 (closed symbol) by ELISA. The mean specific IgG titres are expressed as the reciprocal plasma dilution at an absorbance of 0.6 (V1: circle, V2: square, V4: triangle up, V5: triangle down, V6: diamond, V7: hatched triangle, and V8: hatched circle)

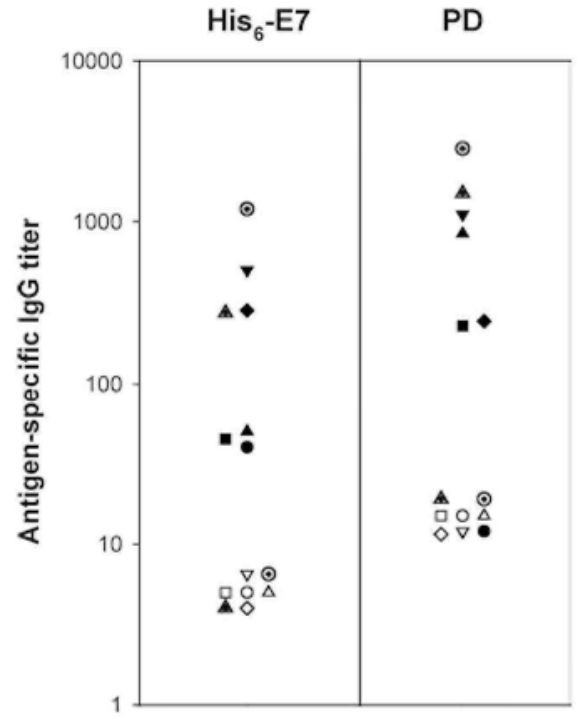

\section{Discussion}

PD-E7, a fusion protein comprising a mutated HPV-16 E7 and the amino-terminal third of $H$. influenzae protein $\mathrm{D}$, has been shown to effectively cure mice from HPV-16-positive growing tumour, when administrated with the GSK adjuvant AS02B [9]. The aim of the present study was to evaluate the immunogenicity of this vaccine in CIN patients. Women harbouring oncogenic HPV, and not only HPV-16, were enrolled because T-cell crossreactivity between HPV types has been previously described [7, 10, 37]. Seven patients, five HPV-16-positive CIN3 and two CIN1, received three intramuscular injections of PD-E7 with adjuvant, whereas three CIN1 patients were injected with a placebo. Within the 8 weeks after vaccination, the majority of the patients developed significant systemic vaccine antigen-specific IFN- $\gamma(5 / 7)$ and antibody (7/7) responses. No antibody response was detected in the placebo patients and only one of them showed an IFN- $\gamma$ response. Interestingly, this patient showed the highest viral load (data not shown).

Although this clinical trial has been performed on a relatively small number of patients, some interesting findings were made. First, we demonstrated that CFC is a valid method for the monitoring of T-cell responses after vaccination against HPV-16 E7. HPV-directed cellular immune responses, which are known to play a crucial role in the eradication of HPV-infected cells, are usually weak and difficult to measure. Consequently, most of the studies described memory T-cell responses analysed after several steps of antigenic stimulation [2]. To characterize ongoing E7-specific cellular immune response, we used the sensitive and qualitative CFC technique which had already proven to be useful to monitor T-cell responses after antitumour vaccination [15, 23]. We showed that an overnight in vitro stimulation with the recombinant PD-E7 protein induces a significant percentage of PBMC-derived $\mathrm{CD}^{+} \mathrm{T}$ cells to produce IFN $-\gamma$. We further demonstrated that the specific CD $8^{+}$ IFN- $\gamma$ responses are indeed MHC class I-restricted T-cell responses. IFN- $\gamma$ production was detectable before vaccination both in CIN1 and CIN3 patients. The percentage of IFN- $\gamma$-producing cells determined by CFC was positively correlated with the cytokine level in PBMC supernatant assessed by using a specific ELISA. Second, PD-E7/GSK AS02B was immunogenic in patients harbouring CIN lesions. The majority of the patients (four out of five CIN3 and one out of two CIN1) developed systemic PD-E7-directed T-cell responses after vaccination, characterized by a predominant $\mathrm{CD} 8^{+}$IFN- $\gamma$ response. This phenotypic pattern suggests that vaccination has induced the expected type 1-specific T-cell response. Moreover, the responses that we observed might be immunologically effective; indeed, their levels are in the same range as many antiviral T-cell responses measured with CFC assays [23]. In spite of a transient decrease in anti-PD-E7 T-cell responses detected between weeks 50 to 60 , three vaccine injections generated memory $\mathrm{T}$ cells, at least in $40 \%$ of the responding patients. PD-E7-directed IFN- $\gamma$ response was not significantly modified following placebo injection. All the vaccinated patients (7/7), not the placebo-injected ones (0/3), made significant levels of E7-specific plasmatic IgG with six of them having also produced anti-PD IgG. Accordingly, none of the study patients was positive before treatment $(0 / 10)$. The presence of anti-E7 IgG indirectly proves that vaccination has activated E7-specific CD4 ${ }^{+}$ $\mathrm{T}$ cells. In addition to these systemic immune responses, the vaccination resulted in the infiltration of the CIN3 stroma with $\mathrm{CD}^{+}$and $\mathrm{CD}^{+}$T cells, as previously described [33]. A similar T-cell infiltration was also observed 
in one vaccinated CIN1 patient (data not shown) and could not be documented in the other one because no lesion was detected at the time of biopsy. Third, the cervical lesion disappeared in two vaccinated CIN1 patients whereas one progressed to CIN2 during the protocol (data not shown). Among the placebo CIN1 patients, two spontaneously eliminated their lesion but it must be noticed that these patients had, at the beginning of the clinical protocol, a very low viral load which has been shown to be negatively correlated with viral persistence (data not shown) [13]. These data confirm the frequent spontaneous regression of CIN1 with a low amount of HPV DNA, making this category of patients inappropriate for the evaluation of vaccine efficacy. For that purpose, CIN1 with a high and persistent viral load and CIN3 patients whose lesions regress at a lower rate and progress rather slowly should be more suitable. In CIN3 patients, no viral clearance or lesion regression was observed after vaccination [33]. This lack of clinical response might be related to both the histological evaluation date (too early after the last vaccine injection) and the induction of a too weak immunization. Future studies are planned to determine whether an increase of the clinical assessment window to 5 months, a short period compared with the natural history of CIN [25], is required to observe HPV clearance and histological response after vaccination. On the other hand, our data showed that three vaccine injections generate low antibody responses in all the patients and do not increase specific T-cell responses in all of them.

These findings suggest that a further validation of this vaccine should be performed to determine whether increasing the number of vaccinations could increase the percentage of responding patients and generate a stronger immunity.

It must be noted that we have not definitively proven that all the PD-E7-activated IFN- $\gamma^{+} \mathrm{T}$ cells are actually E7specific. Their relatively high frequencies (ranging between $0.25 \%$ to $1.77 \%$ of blood $\mathrm{CD}^{+} \mathrm{T}$ cells) measured using CFC, are probably related to the global immune response to PD-E7. However, others have reported similar or even higher amounts of virus- or tumour-specific T cells [1]. Presently, the best tools for assessing CD $8^{+}$and $\mathrm{CD}^{+} \mathrm{T}$-cell specificity are tetrameric MHC class I or class II molecules loaded with specific antigenic peptides, but they only allow for the analysis of single specificities and are not predictive of T-cell function [20]. Stimulating PBMCs with pools of Ag-derived synthetic peptides might test a larger range of specificities.

Although the small sample size of this study precludes us from formulating definitive conclusions, our data highlight the potential interest of the PD-E7/GSK AS02B vaccine. The efficacy of this treatment has to be studied, however, in a larger group of CIN patients with a high and persistent load of oncogenic HPV.

\section{Acknowledgements}

We thank GlaxoSmithKline Biologicals, Belgium, for providing the study vaccine. Sonia Pisvin and Renee Gathy provided excellent technical assistance. P.D. and N.J. are supported by the Belgian National Fund for Scientific Research. This work was supported by the Yvonne Boël Foundation, the Belgian National Fund for Scientific Research and the Region Wallonne.

\section{References}

1. Baurain JF, Colau D, van Baren N, Landry C, Martelange V, Vikkula M, Boon T, Coulie PG (2000) High frequency of autologous antimelanoma CTL directed against an antigen generated by a point mutation in a new helicase gene. J Immunol 164:6057

2. Bontkes HJ, de Gruijl TD, van Den Muysenberg AJ, Verheijen RH, Stukart MJ, Meijer CJ, Scheper RJ, Stacey SN, Duggan-Keen MF, Stern PL, Man S, Borysiewicz LK, Walboomers JM (2000) Human papillomavirus type 16 E6/E7-specific cytotoxic T lymphocytes in women with cervical neoplasia. Int J Cancer 88:92

3. Bory JP, Cucherousset J, Lorenzato M, Gabriel R, Quereux C, Birembaut P, Clavel C (2002) Recurrent human papillomavirus infection detected with the hybrid capture II assay selects women with normal cervical smears at risk for developing high grade cervical lesions: a longitudinal study of 3,091 women. Int J Cancer 102:519

4. Chu NR, Wu HB, Wu T, Boux LJ, Siegel MI, Mizzen LA (2000) Immunotherapy of a human papillomavirus (HPV) type 16 E7expressing tumour by administration of fusion protein comprising Mycobacterium bovis bacille Calmette-Guerin (BCG) hsp65 and HPV16 E7. Clin Exp Immunol 121:216

5. Davidson EJ, Boswell CM, Sehr P, Pawlita M, Tomlinson AE, McVey RJ, Dobson J, Roberts JS, Hickling J, Kitchener HC, Stern PL (2003) Immunological and clinical responses in women with vulval intraepithelial neoplasia vaccinated with a vaccinia virus encoding human papillomavirus 16/18 oncoproteins. Cancer Res 63:6032

6. Davies P, Kornegay J, Iftner T (2001) Current methods of testing for human papillomavirus. Best Pract Res Clin Obstet Gynaecol 15:677

7. de Jong A, van der Burg SH, Kwappenberg KM, van der Hulst JM, Franken KL, Geluk A, van Meijgaarden KE, Drijfhout JW, Kenter G, Vermeij P, Melief CJ, Offringa R (2002) Frequent detection of human papillomavirus 16 E2-specific T-helper immunity in healthy subjects. Cancer Res 62:472

8. Galloway DA (2003) Papillomavirus vaccines in clinical trials. Lancet Infect Dis 3:469

9. Gerard CM, Baudson N, Kraemer K, Bruck C, Garcon N, Paterson Y, Pan ZK, Pardoll D (2001) Therapeutic potential of protein and adjuvant vaccinations on tumour growth. Vaccine 19:2583 
10. Goldstone SE, Palefsky JM, Winnett MT, Neefe JR (2002) Activity of HspE7, a novel immunotherapy, in patients with anogenital warts. Dis Colon Rectum 45:502

11. Hallez S, Detremmerie O, Giannouli C, Thielemans K, Gajewski TF, Burny A, Leo O (1999) Interleukin-12-secreting human papillomavirus type 16-transformed cells provide a potent cancer vaccine that generates E7-directed immunity. Int J Cancer 81:428

12. Ho GY, Burk RD, Klein S, Kadish AS, Chang CJ, Palan P, Basu J, Tachezy R, Lewis R, Romney S (1995) Persistent genital human papillomavirus infection as a risk factor for persistent cervical dysplasia. J Natl Cancer Inst 87:1365

13. Ho GYF, Palan PR, Basu J, Romney SL, Kadish AS, Mikhail M, Wassertheil-Smoller S, Runowicz C, Burk RD (1998) Viral characteristics of human papillomavirus infection and antioxidant levels as risk factors for cervical dysplasia. Int J Cancer 78:594

14. Jochmus I, Schafer K, Faath S, Muller M, Gissmann L (1999) Chimeric virus-like particles of the human papillomavirus type 16 (HPV 16) as a prophylactic and therapeutic vaccine. Arch Med Res 30:269

15. Karanikas V, Lodding J, Maino VC, McKenzie IF (2000) Flow cytometric measurement of intracellular cytokines detects immune responses in MUC1 immunotherapy. Clin Cancer Res 6:829

16. Kast WM, Feltkamp MC, Ressing ME, Vierboom MP, Brandt MP, Melief CJ (1996) Cellular immunity against human papillomavirus associated cervical cancer. Semin Virology 7:117

17. Kaufmann AM, Stern PL, Rankin EM, Sommer H, Nuessler V, Schneider A, Adams M, Onon TS, Bauknecht T, Wagner U, Kroon K, Hickling J, Boswell CM, Stacey SN, Kitchener HC, Gillard J, Wanders J, Roberts JS, Zwierzina H (2002) Safety and immunogenicity of TAHPV, a recombinant vaccinia virus expressing modified human papillomavirus (HPV)-16 and HPV-18 E6 and E7 genes, in women with progressive cervical cancer. Clin Cancer Res 8:3676

18. Kjaer SK, van den Brule AJ, Paull G, Svare EI, Sherman ME, Thomsen BL, Suntum M, Bock JE, Poll PA, Meijer CJ (2002) Type specific persistence of high risk human papillomavirus (HPV) as indicator of high grade cervical squamous intraepithelial lesions in young women: population based prospective follow up study. BMJ 325:572

19. Klencke B, Matijevic M, Urban RG, Lathey JL, Hedley ML, Berry M, Thatcher J, Weinberg V, Wilson J, Darragh T, Jay N, Da Costa M, Palefsky JM (2002) Encapsulated plasmid DNA treatment for human papillomavirus 16-associated anal dysplasia: a phase I study of ZYC101. Clin Cancer Res 8:1028

20. Klenerman P, Cerundolo V, Dunbar PR (2002) Tracking T cells with tetramers: new tales from new tools. Nat Rev Immunol 2:263

21. Ling M, Kanayama M, Roden R, Wu T (2000) Preventive and therapeutic vaccines for human papillomavirus-associated cervical cancers. J Biomed Sci 7:341

22. Liu DW, Tsao YP, Kung JT, Ding YA, Sytwu HK, Xiao X, Chen SL (2000) Recombinant adeno-associated virus expressing human papillomavirus type 16 E7 peptide DNA fused with heat shock protein DNA as a potential vaccine for cervical cancer. J Virol 74:2888

23. Maecker HT, Auffermann-Gretzinger S, Nomura LE, Liso A, Czerwinski DK, Levy R (2001) Detection of CD4 T-cell responses to a tumor vaccine by cytokine flow cytometry. Clin Cancer Res 7:902s

24. Mantovani F, Banks L (2001) The human papillomavirus E6 protein and its contribution to malignant progression. Oncogene 20:7874

25. Melnikow J, Nuovo J, Willan AR, Chan BK, Howell LP (1998) Natural history of cervical squamous intraepithelial lesions: a metaanalysis. Obstet Gynecol 92:727

26. Milojkovic M (2002) Residual and recurrent lesions after conization for cervical intraepithelial neoplasia grade 3 . Int J Gynaecol Obstet $76: 49$

27. Muderspach L, Wilczynski S, Roman L, Bade L, Felix J, Small LA, Kast WM, Fascio G, Marty V, Weber J (2000) A phase I trial of a human papillomavirus (HPV) peptide vaccine for women with high-grade cervical and vulvar intraepithelial neoplasia who are HPV 16 positive. Clin Cancer Res 6:3406

28. Munger K, Basile JR, Duensing S, Eichten A, Gonzalez SL, Grace M, Zacny VL (2001) Biological activities and molecular targets of the human papillomavirus E7 oncoprotein. Oncogene 20:7888

29. Nagai Y, Maehama T, Asato T, Kanazawa K (2000) Persistence of human papillomavirus infection after therapeutic conization for CIN 3: is it an alarm for disease recurrence? Gynecol Oncol 79:294

30. Noel J, Lespagnard L, Fayt I, Verhest A, Dargent J (2001) Evidence of human papilloma virus infection but lack of Epstein-Barr virus in lymphoepithelioma-like carcinoma of uterine cervix: report of two cases and review of the literature. Hum Pathol 32:135

31. Reich O, Lahousen M, Pickel H, Tamussino K, Winter R (2002) Cervical intraepithelial neoplasia III: long-term follow-up after coldknife conization with involved margins. Obstet Gynecol 99:193

32. Santin AD, Bellone S, Gokden M, Cannon MJ, Parham GP (2002) Vaccination with HPV-18 E7-pulsed dendritic cells in a patient with metastatic cervical cancer. N Engl J Med 346:1752

33. Simon P, Buxant F, Hallez S, Burny A, Fayt I, Anaf V, Noel JC (2003) Cervical response to vaccination against HPV16 E7 in case of severe dysplasia. Eur J Obstet Gynecol Reprod Biol 109:219

34. Steller MA, Gurski KJ, Murakami M, Daniel RW, Shah KV, Celis E, Sette A, Trimble EL, Park RC, Marincola FM (1998) Cellmediated immunological responses in cervical and vaginal cancer patients immunized with a lipidated epitope of human papillomavirus type 16 E7. Clin Cancer Res 4:2103

35. van der Burg S, Ressing ME, Kwappenberg KM, de Jong A, Straathof K, de Jong J, Geluk A, van Meijgaarden KE, Franken KL, Ottenhoff TH, Fleuren GJ, Renter G, Melief CJ, Offringa R (2001) Natural T-helper immunity against human papillomavirus type 16 (hpv16) e7-derived peptide epitopes in patients with hpv16-positive cervical lesions: identification of 3 human leukocyte antigen class IIrestricted epitopes. Int J Cancer 91:612

36. van Driel WJ, Ressing ME, Kenter GG, Brandt RM, Krul EJ, van Rossum AB, Schuuring E, Offringa R, Bauknecht T, Tamm- 
Published in: Cancer Immunology, Immunotherapy (2004), vol. 53, iss. 7, pp. 642-650. Status : Postprint (Author's version)

Hermelink A, van Dam PA, Fleuren GJ, Kast WM, Melief CJ, Trimbos JB (1999) Vaccination with HPV16 peptides of patients with advanced cervical carcinoma: clinical evaluation of a phase I-II trial. Eur J Cancer 35:946

37. Williams OM, Hart KW, Wang ECY, Gelder CM (2002) Analysis of CD4( + ) T-cell responses to human papillomavirus (HPV) type 11

L1 in healthy adults reveals a high degree of responsiveness and cross-reactivity with other HPV types. J Virol 76:7418-7429

38. zur Hausen H (2002) Papillomaviruses and cancer: from basic studies to clinical application. Nat Rev Cancer 2:342 